\title{
Therapy of autoinflammatory diseases: a review of the literature
}

\author{
NM ter Haar*, J Frenkel \\ From 18th Pediatric Rheumatology European Society (PReS) Congress \\ Bruges, Belgium. 14-18 September 2011
}

\section{Background}

The evidence for the therapy of autoinflammatory diseases is limited. There are few randomized controlled trials (RCTs) or cohort studies.

\section{Aim}

To provide an up to date literature review about the response to treatment in autoinflammatory diseases.

\section{Methods}

A literature search using Medline and Embase was performed regarding the treatment of Blau's syndrome, Behçet's disease, CAPS, CRMO, DIRA, FMF, MKD, NLRP12-mediated periodic fever, PAPA, PFAPA and TRAPS.

\section{Results}

RCTs provide evidence for rilonacept and canakinumab in CAPS, colchicine in FMF and (adeno)tonsillectomy in PFAPA syndrome. For Behçet disease, RCTs have been conducted on the effect of several drugs, including colchicine, azathioprine, cyclosporine A, interferon alfa, etanercept, sucralfate suspension and pimecrolimus. Descriptive studies suggest that NSAIDs and corticosteroids are highly effective in respectively CRMO and PFAPA and moderately effective in the other diseases. Etanercept and anakinra appear to induce a complete or partial response in most patients with MKD, TRAPS, PAPA and colchicine-resistant FMF. Anakinra appears to induce a complete response in the majority of the CAPS and DIRA patients, but seems to be less effective in NLRP12-mediated periodic fever. Complete remission by infliximab is described in cases with Blau's syndrome, CRMO, PAPA, refractory FMF and Behçet disease, but

\footnotetext{
* Correspondence: n.m.terhaar@students.uu.nl

Department of Pediatrics University Medical Centre Utrecht, Netherlands
}

the effect of infliximab in TRAPS patients seems to be disappointing.

\section{Conclusion}

Reported findings were compared to the results of the Eurofever registry. These combined results could serve as a base for therapeutic guidelines and identify candidate drugs for future therapeutic trials.

Published: 14 September 2011

doi:10.1186/1546-0096-9-S1-P15

Cite this article as: ter Haar and Frenkel: Therapy of autoinflammatory diseases: a review of the literature. Pediatric Rheumatology 2011 9(Suppl 1):P15.

Submit your next manuscript to BioMed Central and take full advantage of:

- Convenient online submission

- Thorough peer review

- No space constraints or color figure charges

- Immediate publication on acceptance

- Inclusion in PubMed, CAS, Scopus and Google Scholar

- Research which is freely available for redistribution

Submit your manuscript at www.biomedcentral.com/submit
C Biomed Central

\section{Ciomed Central}

